\title{
Transanastomotic Feeding Jejunostomy with Nasogastric Aspiration in Case of Jejuno-ileal Atresia for early Feeding and Better out Come; Five year experience
}

\author{
Punit Srivastava ${ }^{1 *}$ and Richa Jaiman ${ }^{2}$ \\ ${ }^{1}$ Dept of Pediatric Surgery, SN Medical College, Agra, India \\ ${ }^{2}$ Dept of Surgery, SN Medical College, Agra, India
}

\section{ABSTRACT}

Aim: To evaluate the role of Transanastomotic feeding jejunostomy with nasogastric aspiration in case of-jejuno-ileal atresia

Methods: Transanastomotic feeding jejunostomy with end-to-end anastomosis was done in 25 neonates ofjejuno-ileal atresia and the results were compared with traditional method of end to end anastomosis in 25 cases of atresia without transanostomotic feeding jejunostomy.

Results: We found less mortality and morbidity (1\%) in anastomosis with transanostomotic feeding jejunostomy technique as compared to anastomosis without feeding jejunostomy (20\%).

Conclusions: We recommend this technique, as anastomosis is safe with early feeding with good outcome

Keywords: Transanostomotic Feeding Jejunostomy, Jejuno-Ileal Atresia

\section{Introduction}

Jejunoileal atresias are major causes of neonatal intestinal obstruction. It can occur anywhere along the gastrointestinal tract, and the anatomic location of the obstruction determines the clinical presentation. Most newborns with intestinal obstruction present with abdominal distention and bilious emesis in the first 2 days of life. Bilious vomiting in the neonate should be considered secondary to a mechanical obstruction until proved otherwise, and emergency surgical evaluation is warranted in every newborn with this symptom. Many anastomotic techniques have been devised for intestinal atresia. Theanostomotic leak can occur due to disparity in luminal diameter, poor nutrition and technique which can cause high morbidity and mortality. To reduce this we performed end-end anastomosis with transanastomotic feeding jejunostomy which give better outcome.

\section{Material and Methods}

The present study has been conducted from September 2010 to September 2015. Neonates presented within one to 4 days of life. Out of them, 10 patients were less than $24 \mathrm{~h}$ and 15 were more than $24 \mathrm{~h}$ in both groups. Out of 50 patients, 30 were males and 20 were females. Among 50 patients, 16 were under $2 \mathrm{~kg}, 26$ were between 2 to 2.5 $\mathrm{kg}$, and 8 were more than $2.5 \mathrm{~kg}$. Jejunoileal atresia was diagnosed on the basis of history, clinical examination, and x-ray of abdomen. Our technique of performing anastomosis with transanastomotic feeding jejunostomy was compared with that of conventional end to end anastomosis without feeding jejunostomy in jejuno-ileal atresia. We selected 25 neonates randomly (test group) on whom anastomosis with transanastomotic feeding jejunostomy was done and results were compared with that of 25 neonates (control group) in which traditional end to end anastomosis without transanastomotic feeding jejunostomy were done. Both the groups were age and weight matched. We excluded type IIIb and IV atresia and patients of major congenital anomalies. Entire surgery was performed by the same surgeon. Exploration of abdomen was done by right transverse supra-umbilical incision. Proximal dilated and distal constricted bowel segments were identified. Proximal distended segment was deflated and $5-10 \mathrm{~cm}$ of distended bowel was resected. Margin was cut obliquely starting from antimesenteric border to mesenteric border so that the $1 \mathrm{~cm}$ difference created between antimesenteric and mesenteric border simultaneously preserving mesenteric vascular supply. Distal atretic bowel wall was cut obliquely making cut margin similarly creating $1 \mathrm{~cm}$ difference between antimesenteric and mesenteric border. Proximal feeding jejunostomy was done by $6 \mathrm{fr}$ feeding tube which was taken out per abdominal rout and fixed to abdominal skin [Fig 1] Anastomosis was performed in single layer interrupted by 5-0 vicryl sutures. We first approximate mesentery of 
adjacent bowel. Inverting sutures were taken in interrupted manner. Two or three interrupted stitches were taken commencing from mesenteric border and anastomosis was progressed toward antimesenteric border from opposite direction, thereby completing anastomosis. Last two to three anterior stitches were taken full thickness Lembert, which gives better serosa to serosa approximation. Finally, mesenteric defect was closed. Prophylactic drain placed in peritoneal cavity for any collection .

Post-operatively, patients were given IV fluids, antibiotics, cholestyramine, and kept nil by mouth and continuous nasogastric aspiration by infant feeding tube. Patients were given feed from jejunostomy tube feed on day 3-5 post-operatively depend on presence of bowel sound and passing meconium routinely and full oral feed $10^{\text {th }}-12^{\text {th }}$ postop day depending upon tolerability. Jejunostomy feed tube can be safely removed on 12-14 day[Fig-2]. Average hospital stay was 14 days. All the patients were regularly followed up in OPD.

\section{Results}

Out of 50 neonates, 25 underwent end to end anastomosis with feeding jejunostomy and 25 were anastomosis without feeding jejunostomy tube. Only, one patient in our technique died due to septicemia and low birth weight mortality rate was 1 in 25 (4\%). Five patients died out of 25 in anastomosis without feeding jejunostomy, mortality rate was 5 in 25 $(20 \%)$ due to leak at the site of anastomosis. In our technique, jejunostomy feeds were started on $5.56 \pm 0.76$ whereas in anastomosis without jejunostomy feed it was on $9.76 \pm$ 0.72 day. There is a significant difference between the day of starting feeding between the groups ( $\mathrm{t}$ value=19.9025; $\mathrm{df}=48 ; \mathrm{p}$-value $=0.000)$. In routine anastomotic without jejunostomy technique, 6 patients out of 25 (24\%) developed features of subacute intestinal obstruction characterized by abdominal distention, vomiting, and excess nasogastric aspirate but had resolved upon conservative management. However, in our technique none of the patients developed features of intestinal obstruction.

Tabel

\begin{tabular}{|l|c|c|c|}
\hline Features & $\begin{array}{c}\text { Anastomosis with } \\
\text { jejunostomy }(\mathbf{n = 2 5})\end{array}$ & $\begin{array}{c}\text { Anastomosis without } \\
\text { jejunostomy (n=25) }\end{array}$ & $\begin{array}{c}\text { Significance difference } \\
\text { (t value) }\end{array}$ \\
\hline $\begin{array}{l}\text { Age } \\
\begin{array}{l}1 .<24 \mathrm{hr} \\
2 .>24 \mathrm{hr}\end{array}\end{array}$ & 10 & 15 & 15 \\
\hline Mortality & 10 & $5(20 \%)$ & \\
\hline Subacute obstruction & $1(4 \%)$ & $6(24 \%)$ & \\
\hline Day of feeding & 0 & $9.76 \pm 0.72$ day & $\begin{array}{c}(t \text { value }=19.9025 ; d f= \\
48 ; p-v a l u e=0.000)\end{array}$ \\
\hline
\end{tabular}

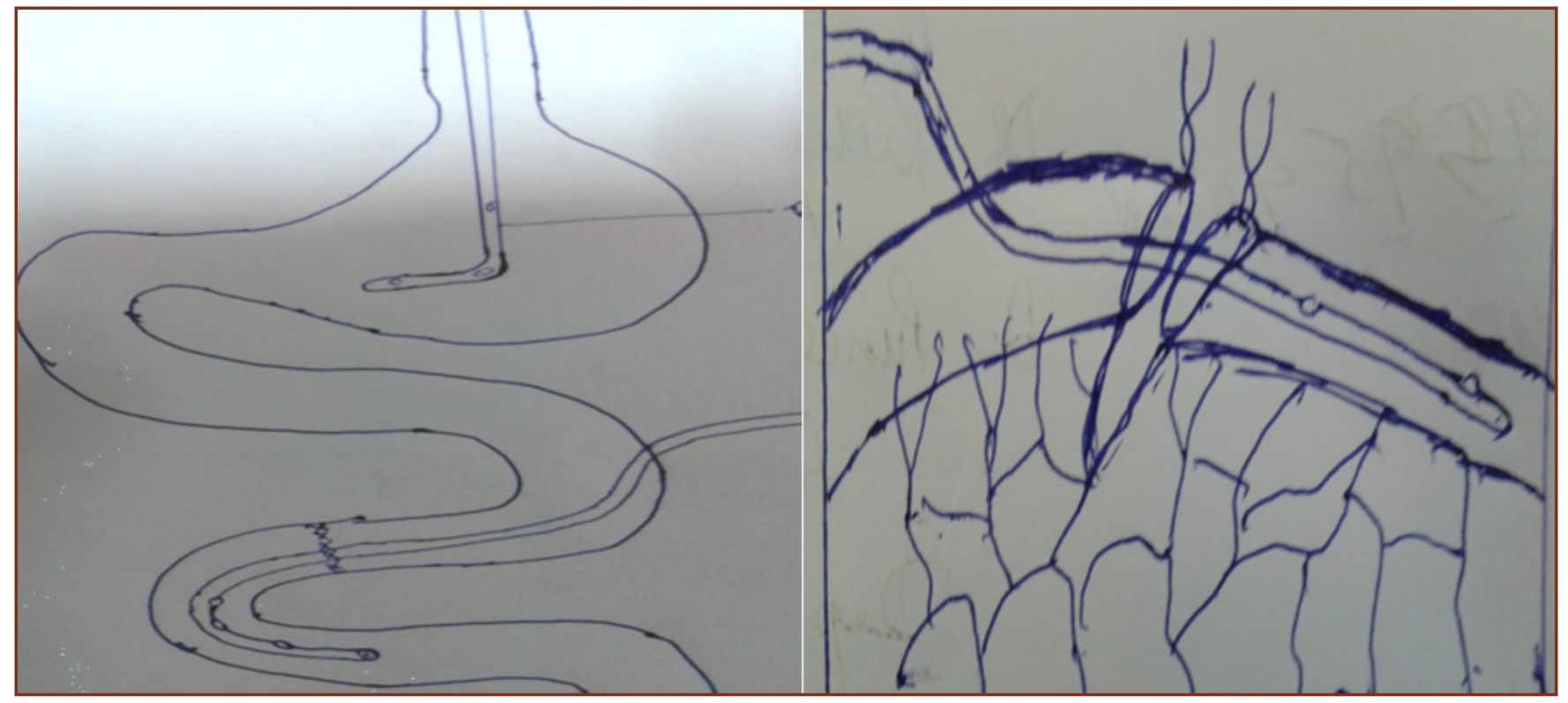

Fig. 1: Transanastomotic feeding jejunostomy with nasogastric aspiration. 


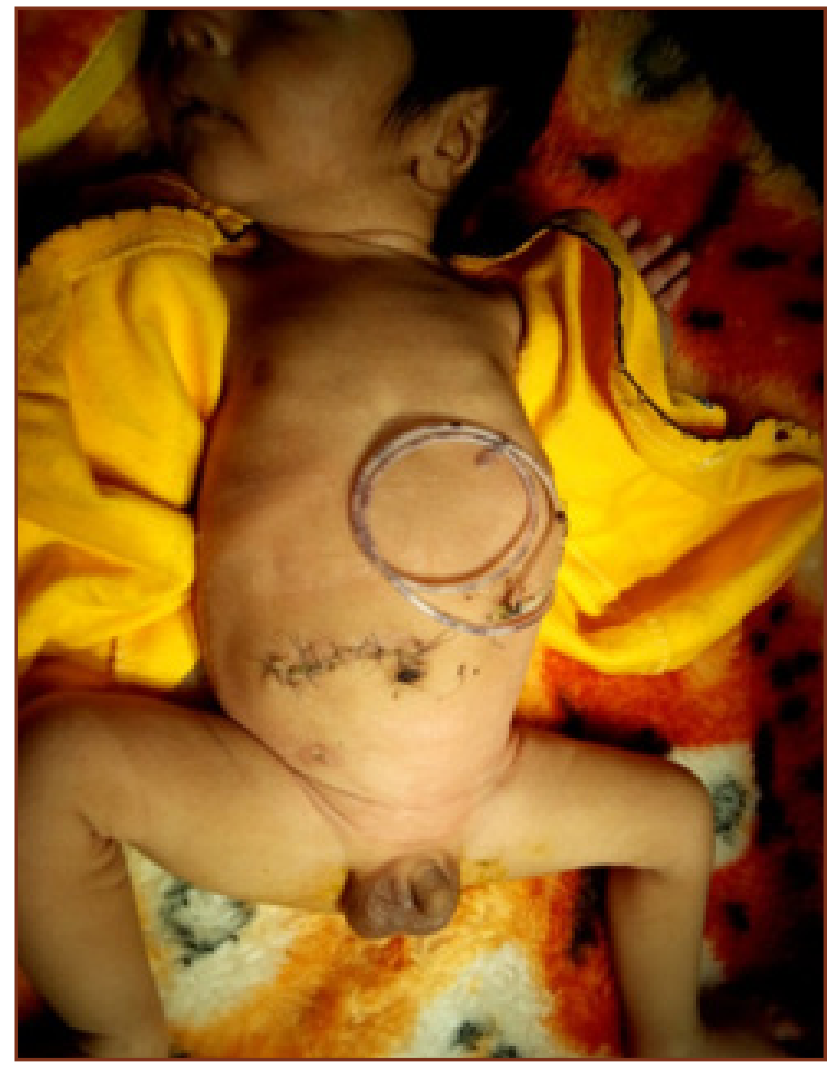

Fig. 2: Transanastomotic feeding jejunostomy with Infant feeding tube $6 \mathrm{fr}$ in situ.

\section{Discussion}

Many anastomotic techniques have been advised for intestinal atresia. The procedures can be classified into two types: (1) widening of caliber of the diminutive distal bowel and (2) reducing the caliber of the large proximal bowel. End to back, end to side, and end to end oblique anastomosis that is described belong to first type, and tapering enteroplasty[1] followed by end to end anastomosis into the second type. In 1894, Wanitschek [2] attempted first resection anastomosis for the intestinal atresia unsuccessfully. End-to-back anastomosis[3,4] shows neither technical problems nor post-operative anastomotic functional obstruction if the caliber ratio between the proximal and distal atretic bowels is not large. However, as the caliber ratio increases longitudinal axis deviation between proximal and distal bowels gradually becomes close to $90^{\circ}$, resembling end to side anastomosis, which easily results in functional obstruction. It seems to be very difficult to perform functional end-to-back anastomosis in cases where caliber ratio is more than 4. Gambee's [5] single layer anastomosis, which was originally performed in an end to end anastomotic fashion, has no anastomotic axial deviation, but the caliber ratio must be limited to four values to perform this procedure safely.[6] Halsted's aseptic anastomosis[7] also resulted in no anastomosis axial deviation and is reported to be possible in cases with a caliber ratio of upto five values although there must be limit for its indication.[8]

Tapering jejunoplasty[9] of the proximal dilated segment followed by construction of end to end jejunostomy has been reported to be useful[10-12]for large caliber difference. However, this method has disadvantage of bowel dismotility and axial deviation. Another technique described by Patil et al in which linear anastomosis was done excising a circular disc of proximal dilated bowel and anastomosed to narrowed distal bowel in single layer, but in this case there was luminal disparity in proximal and distal segment causing leakage at anastomotic site and increased morbidity and mortality rate.[13]

In our technique, we cut proximal bowel in concave fashion after 5-10 $\mathrm{cm}$ bowel resection and distal bowel in convex fashion and performed anastomosis in interrupted manner with vicryl 5-0 (round body) with knot inside. The jejunostomy opening made and 6 fr infant feeding tube passed intraluminaly across anastomotic line and was placed in distal bowel segment $5-6 \mathrm{~cm}$ beyond anastomosis. Jejunostomy tube was taken outside per-abdomen for feed. The resultant anastomosis is patulous one without bowel angulations. Furthermore, early feed start to give proper nutrition \& also aid to distal bowel dilataion. Proximal nasogastric decompressive aspiration leads to decrease chances of anostomotic leak. In fact, there was no leak in our technique as demonstrated by post-operative dye study.

\section{Conclusion}

This technique of end to end oblique anastomosis results in wide and early functioning anastomosis. The mortality and morbidity rate is reduced. Hospital stay is also reduced. Total parenteral nutrition is not required. We believed that improved results are due to fewer angulations, better alignment of adjacent bowel loop, good early nutrition and wider functional anastomotic area resulting in linear flow of effluent. So, we recommend this method of bowel anastomosis with feeding jejunostomy in cases of jejunoileal atresia as a technical advancement.

\section{References}

1. Gray SW, Skandalakis Jl. Embryology for surgeons. Philadelphia: Saunders; 1972. p. 151.

2. Benson CD, Llyod JR, Smith JD. Resection and primary anastomosis in management of stenosis and atresia of jejunum and ileum.Pediatrics. 1960;26:265-72. 
3. Nixon HH, Tawes R. Etiology and treatment of small intestinal atresia: Analysis of a series of 127 jejunoilealaresia and comparison with 62 duodenal atresia. Surgery. 1971;69:41-51.

4. Gambee LP. A single layer open intestinal anastomosis applicable to the small as well as large intestine. West J SurgObstet Gynecol. 1951;59:1-8.

5. Kimura S, Tomooka $\mathrm{Y}$, Inao A. Intestinal anastomosis by Gambee's single layer anastomosis in infants. J JpnSurg Soc. 1980;81:1115-6.

6. Halsted WS. Circular suture of the intestine: An experimental study. Am J Med Sci. 1887;94:436-41.

7. Kimura K, Tsugawa T, Matsumoto Y. Halsted's anastomosis in intestinal atresia. J JpnSurg Soc. 1980;81:1113-4.
8. Thomas CG. Jejunoplasty for correction of jejunal atresia. SurgGynecol Obstet. 1969;129:545-6.

9. Howard ER, Othersen HB. Proximal jejunoplasty in the treatment of jejunal atresia. J Pediatr Surg. 1973;8:685-90.

10. Thomas CG, Carter JM. Small intestinal atresia: The critical role of a functioning anastomosis. Ann Surg. 1974;179:663-70.

11. Grosfeld JL, Ballantine TV, Shoemaker R. Operative management of intestinal atresia and stenosis based on pathological finding. J Pediatr Surg. 1979;14:368-75.

12. Patil VK, Kulkarni BK, Jiwane A, Kothari P, Poul S. Intestinal atresia: An end to end anastomotic technique. PediatrSurg Int. 2001;17:661-3.

13. Evans CH. Atresia of gastrointestinal tract. SurgGynecol Obstet. 1951;92:61-5.

*Corresponding author:

Dr. Puneet Srivastava, Assistant Professor Surgery, S N Medical College Agra UP, India

Phone: +91 09319966783

Email: drpunit979@gmail.com 